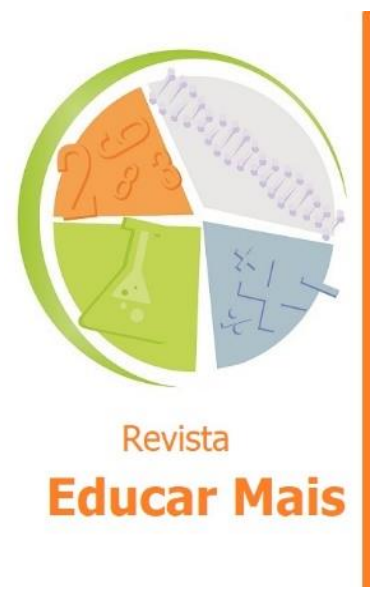

\title{
Educação Infantil em tempo integral: o que dizem as professoras?
}

\section{Full-time early childhood education: what do the teachers say?}

Educación Infantil a tiempo completo: ¿qué dicen las profesoras?

Simone Ferreira Duarte ${ }^{1}$; Franceila Auer2; Rennati Taquini ${ }^{3}$; Vania Carvalho de Araújo $^{4}$

\section{RESUMO}

Este artigo expõe parte dos resultados de um estudo exploratório realizado a partir de entrevistas semiestruturadas com 34 professoras de dez municípios do estado do Espírito Santo, que atuam em creches e pré-escolas públicas urbanas e rurais com atendimento em tempo integral. Tem por objetivo discorrer sobre as percepções das professoras em relação à educação infantil em tempo integral, considerando três categorias analíticas: implementação do tempo integral, práticas pedagógicas e os desafios encontrados. Os resultados apontam que a implementação do atendimento em tempo integral foi motivada pela necessidade de trabalho extradomiciliar, atrelada às condições socioeconômicas das famílias, tais como situação de pobreza, risco e vulnerabilidade social. Em relação às práticas pedagógicas, as professoras revelam centralidade no trabalho de proteção e de provisão das crianças. A escassez de recursos materiais, a falta de transporte para a realização de passeios, o cansaço das crianças em virtude da longa permanência na instituição, bem como a ausência de professores durante toda a jornada são considerados desafios para a garantia de uma experiência em tempo integral com qualidade.

Palavras-chave: Educação infantil; Tempo integral; Professoras.

\section{ABSTRACT}

This paper presents part of the results of an exploratory study conducted based on semi-structured interviews with 34 teachers from ten municipalities in the state of Espirito Santo, who work in public urban and rural kindergartens and pre-schools with full-time care. Its aim is to discuss the teachers' perceptions regarding fulltime early childhood education, considering three analytical categories: full-time implementation, pedagogical practices and the challenges found. The results indicate that the implementation of full-time care was motivated by the need for work outside the home linked to the socioeconomic conditions of families, such as poverty, risk and social vulnerability. In relation to pedagogical practices, teachers reveal centrality in the work of protection and provision of children. The shortage of material resources, the lack of transportation to take children out,

${ }^{1}$ Graduada em Pedagogia e Professora da Educação Infantil na Sensekids escola Montessoriana de Vitória, Vitória/ES - Brasil. E-mail: monnefduarte@gmail.com

${ }^{2}$ Graduada em Pedagogia, Mestra em Educação e Professora da Educação Infantil na Prefeitura Municipal de Vitória, Vitória/ES - Brasil. E-mail: auerfranceila@gmail.com

${ }^{3}$ Graduada em Pedagogia e Professora da Educação Infantil e das Séries Iniciais na Prefeitura Municipal de Guarapari, Guarapari/ES - Brasil. E-mail: rennati@gmail.com

${ }^{4}$ Pós-Doutora em Educação e Professora titular do Centro de Educação e do Programa de Pós-Graduação em Educação da Universidade Federal do Espírito Santo (UFES), Vitória/ES - Brasil. E-mail: vcaraujoufes@gmail.com 
the tiredness of children due to the long stay in the institution, as well as the absence of teachers throughout the day are considered challenges for ensuring a full-time care experience with quality.

Keywords: Early childhood education; Full-time; Teachers.

\section{RESUMEN}

Este artículo presenta parte de los resultados de un estudio exploratorio realizado a través de entrevistas semiestructuradas con 34 profesoras de diez municipios del estado de Espírito Santo, que trabajan en la educación infantil y en las guarderías públicas urbanas y rurales con atención a tiempo completo. Su objetivo es discutir las percepciones de las profesoras acerca de la educación infantil a tiempo completo, teniendo en cuenta tres categorías de análisis: la implementación a tiempo completo, las prácticas pedagógicas y los desafíos encontrados. Los resultados indican que la implementación del cuidado a tiempo completo fue motivada por la necesidad de trabajo extradomiciliar vinculada a las condiciones socioeconómicas de las familias, como la pobreza, el riesgo y la vulnerabilidad social. En cuanto a las prácticas pedagógicas, las profesoras revelan la centralidad en el trabajo de protección y provisión de los niños. La escasez de recursos materiales, la falta de transporte para las salidas, el cansancio de los niños debido a la larga estancia en la institución, así como la ausencia de profesores a lo largo del día se consideran retos para garantizar una experiencia de tiempo completo con calidad.

Palabras clave: Educación infantil; Tiempo completo; Profesoras.

\section{INTRODUÇÃO}

O reconhecimento da Educação Infantil como primeira etapa da Educação Básica aliada à educação como dever do Estado (BRASIL, 1996; BRASIL, 1988), constitui-se como um importante marco do direito à educação da primeira infância. Entretanto, as especificidades atribuídas por esses documentos à primeira etapa da Educação Básica parecem não se estender, significativamente, ao contexto de sua oferta em tempo integral. Historicamente, a jornada em tempo integral nas creches, por exemplo, não foi concebida como uma questão diretamente relacionada ao campo da educação, mas como uma resposta à vasta utilização do trabalho feminino e à nova institucionalidade moral, sanitária e econômica emergente (KUHLMANN JR., 2000).

A formalização do direito à educação passa a vigorar com a promulgação da Constituição da República (BRASIL, 1988) e o reconhecimento da Educação Infantil como um direito de todas as crianças de zero aos cinco anos de idade é reforçado pelo Estatuto da Criança e do Adolescente (ECA) ao afirmálas sujeitos de direitos (BRASIL, 1990), passando a ser "[...] responsabilidade do poder público municipal oferecer creches e pré-escolas a todas as crianças cujas famílias desejem esses serviços ou deles necessitem" (NUNES; CORSINO, 2012, p. 17). Ou seja, a partir desse momento o acesso à Educação Infantil passa a ser de todas as crianças e não apenas daquelas cujas mães estão inseridas no mercado de trabalho, ainda que o art.70 da Constituição da República (BRASIL, 1988) destaque a assistência gratuita prevista aos filhos e às filhas pequenos (as) de mães e pais trabalhadores.

O reconhecimento da Educação Infantil na política educacional pela Lei de Diretrizes e Bases da Educação Nacional - LDB (BRASIL, 1996) deixa entrever um avanço histórico sem precedentes na forma de conceber a proteção social das crianças pequenas como um direito extensivo também ao campo da educação, em que proteção e provisão aliadas ao cuidar e educar como práticas indissociáveis do processo educativo transformam-se em prerrogativas de cidadania e de direitos. 
Mais tarde, articuladas às Diretrizes Nacionais para a Educação Básica são publicadas as Diretrizes Curriculares Nacionais para a Educação Infantil (DCNEIS) (BRASIL, 2010), documento que corrobora a Educação Infantil como primeira etapa da Educação Básica, mediante a obrigatoriedade do Estado em garantir a sua oferta pública, gratuita e de qualidade. A criança assume a centralidade no planejamento curricular voltado para o seu desenvolvimento integral, por meio de proposta pedagógica pautada em princípios éticos, políticos e estéticos, tendo como eixos norteadores as interações e as brincadeiras. Além disso, organiza o tipo de atendimento na Educação Infantil, considerando o tempo em que as crianças permanecem na instituição, seja em jornada de tempo parcial (mínimo de quatro horas diárias), seja em jornada de tempo integral (igual ou superior a sete horas diárias) (BRASIL, 2010).

Em 2014, é aprovado o Plano Nacional de Educação (PNE) (BRASIL, 2014) que, de modo geral, apresenta como objetivos a universalização do atendimento escolar e a melhora da qualidade da Educação Básica nacional. O PNE é composto por 10 metas divididas em estratégias elaboradas para elucidar seu cumprimento. Há que se destacar que a Meta 6 volta-se exclusivamente para a educação integral em tempo integral, nos revelando uma ascendente preocupação com esse tipo de atendimento, visto que, na versão anterior do documento, não havia tal meta. De acordo com o PNE, é definida educação em tempo integral aquela destinada ao aluno ou à aluna que permanece sob responsabilidade da escola por tempo superior a sete horas diárias durante todo o ano letivo. 0 documento apresenta, ainda, que as escolas destinadas ao atendimento em tempo integral sejam, prioritariamente, construídas em comunidades pobres ou com crianças vulneráveis socialmente (BRASIL, 2014), o que nos leva "[...] a problematizar as políticas adotadas para a educação infantil, considerando a sua experiência em tempo parcial e em tempo integral" (ARAÚJO; AUER; TAQUINI, 2021, p. 18).

Alguns estudos demonstram que as diversas experiências de atendimento em tempo integral no país têm se constituído de forma precária no que tange à estrutura física das instituições, à qualificação profissional, à consolidação de um projeto político pedagógico consistente, à ampliação de possibilidades de participação das crianças nos diversos contextos sociais, além de apresentar como característica marcante um processo escolarizante precoce (SOUZA, 2012; OLIVEIRA, 2012; MARCHIORI, 2012; RODRIGUES, 2012; BERNARDES, 2012; JUNCKES, 2015; CASSINS, 2016). Assim, tendo em vista que a educação integral vem se caracterizando, sobretudo, como a permanência das crianças por mais tempo nas instituições de Educação Infantil, fazem-se necessários estudos acerca dos fatores que atravessam as práticas pedagógicas na Educação Infantil em tempo integral, uma vez que a temática é recente no campo das pesquisas educacionais. ${ }^{i}$

De modo geral, observamos que os estudos afirmam a existência de seletividade na oferta de vagas e a predominância de municípios que adotam como critério para matrícula a condição de risco e vulnerabilidade social, pobreza e exclusão. Portanto, "[...] as crianças de diferentes classes sociais podem não estar compartilhando um tempo comum estendido, uma vez que a política de educação infantil em tempo integral parece destinar-se a um público específico" (ARAÚJO; AUER; TAQUINI, 2021, p. 17). A esse respeito, Peixoto, Schuchter e Araújo (2015) ressaltam a necessidade do estabelecimento de diretrizes pelas secretarias municipais de educação, para a implementação e organização da Educação Infantil em tempo integral:

[...] é imprescindível estabelecer políticas para a educação infantil como uma possibilidade articuladora de novas vivências e garantidora de direitos às crianças pequenas, superando as correntes prerrogativas que as situam em uma perspectiva 
de política compensatória e preventiva dos males ocasionados pelas mazelas sociais da sociedade contemporânea (PEIXOTO; SCHUCHTER; ARAÚJO, 2015, p. 128).

Corroborando com as reflexões e provocações acerca do entendimento de como a Educação Infantil em tempo integral vem se constituindo ao longo de décadas, pesquisaii coordenada por Araújo (2015) revela que a Educação Infantil em tempo integral já é uma realidade pujante no Brasil e no estado do Espírito Santo. Os dados preliminares do estudo evidenciam que as condições socioeconômicas das famílias e a precarização de vida das crianças aparecem como as grandes questões motivadoras da oferta do tempo integral na Educação Infantil. A despeito da motivação sobre a implementação da educação em jornada ampliada, somos levados a problematizar se as instituições de Educação Infantil estão preparadas para a experiência da educação em tempo integral para as crianças com qualidade socialmente referenciada.

Considerando as razões e anseios observados nas entrevistas dos sujeitos participantes do estudo de Araújo (2015),iii o presente artigo tem por objetivo discorrer sobre as percepções das professoras em relação à Educação Infantil em tempo integral. Para tanto, lançamos como questões de investigação: quais os fatores de natureza social e econômica que contribuíram para a implementação do atendimento na Educação Infantil em tempo integral nas realidades investigadas? Quais as motivações das professoras para atuarem nessas instituições? Quais as características predominantes no trabalho pedagógico realizado com as crianças? Quais os desafios encontrados pelas professoras em suas práticas?

Pesquisas como esta têm sido fundamentais para o entendimento da sociedade em relação à educação das crianças pequenas, entretanto, como destacam Araújo e Peixoto (2017, p. 81), a Educação Infantil em tempo integral ainda aparece como "[...] uma experiência que muitas vezes não corresponde a uma institucionalidade ensejada e arduamente conquistada com a afirmação da educação infantil como primeira etapa da Educação Básica", pois constantemente apresenta-se como um trabalho deslocado de tal experiência. Desta forma, considerando que o tempo integral provoca desafios para a construção de propostas educativas que levem em conta as crianças e suas especificidades, este artigo direciona um olhar para as práticas e estratégias de atendimento da Educação Infantil em tempo integral nas creches e pré-escolas a partir das concepções das professoras.

\section{METODOLOGIA}

Trata-se de um estudo exploratório de caráter qualitativo que tem por intuito "[...] desenvolver, esclarecer e modificar conceitos e ideias, tendo em vista a formulação de problemas mais precisos ou hipóteses pesquisáveis para estudos posteriores" (GIL, 2008, p. 27), abordagem metodológica que busca familiarizar-se com temas poucos estudados. 0 artigo tem por referência a pesquisa coordenada por Araújo (2015), realizada com as professoras de vinte instituições de Educação Infantil em tempo integral de dez municípios do estado do Espírito Santo, situados em contextos urbanos e rurais. Os municípios foram selecionados conforme a legislação aplicada pelo Governo do Estadoiv acerca da divisão geopolítica do Espírito Santo, com base nos seguintes critérios: 1) Oferta de Educação Infantil em Tempo Integral na área urbana e rural; 2) Municípios que possuem instituições que ofertam Educação Infantil ( 0 a 6 anos) exclusivamente em Tempo Integral; 2.1. Municípios que possuem instituições que ofertam Educação Infantil ( 0 a 6 anos) exclusivamente em Tempo Integral levando em consideração maior número de instituições do município; 3) Municípios que possuem 
instituições que ofertam pelo menos uma das etapas da Educação Infantil (creche ou pré-escola) em Tempo Integral.

Conforme as macrorregiões capixabas (Metropolitana; Norte; Central e Sul), foram selecionados os municípios das seguintes Microrregiões: Metropolitana (Vitória), Rio Doce (Linhares); Central Serrana (Santa Leopoldina), Litoral Sul (Anchieta), Sudoeste Serrana (Domingos Martins), Nordeste (Pinheiros), Centro Oeste (Vila Valério), Noroeste (Barra de São Francisco), Centro Sul (Castelo), Caparaó (Ibatiba). A partir dessa delimitação inicial, foram identificados aspectos relevantes a serem considerados na seleção das instituições. Desse modo, na segunda fase, duas instituições de cada município foram selecionadas, de acordo com os critérios de escolha: 1) Possuir instituição em área urbana e na área rural; 2) Contar com atendimento em creche e em pré-escola exclusivamente em tempo integral; 3) Contar com atendimento em creche e pré-escola simultaneamente em tempo integral e parcial. Como alguns municípios selecionados não contemplavam o atendimento simultaneamente em creche ou pré-escola, foi realizado um sorteio para definir a instituição selecionada.

Uma vez feito o convite para todas as professoras que atuam nas creches e pré-escolas com atendimento em tempo integral dos municípios investigados, 34 delas demonstram interesse, assinam um Termo de Consentimento Livre Esclarecido e participam da pesquisa. Foram aplicados questionários semiestruturados, compostos por 17 questões, nas próprias instituições de Educação Infantil em que as professoras lecionam, mediante transcrição escrita simultânea, pelos pesquisadores, das falas das entrevistadas. Dentre as questões, nove relacionadas aos processos e dispositivos para e na "implementação" do tempo integral na Educação Infantil; cinco em referência às "práticas pedagógicas" e outras atividades adotadas pelos docentes no trabalho com as crianças, e três sobre os "desafios" na experiência com o tempo integral. Os dados coletados nos questionários foram organizados a partir de três categorias analíticas: a) implementação do tempo integral; b) práticas pedagógicas e c) desafios. Por meio dessas categorias, procedeu-se a análise descritiva e explicativa dos dados, que possibilita diagnosticar situações e descobrir novas ideias sobre o tema estudado, bem como abranger com precisão os dados coletados na pesquisa, permitindo estabelecer relações entre as categorias de análise investigadas, como esclarece Oliveira (2011). Assim sendo, foi possível discorrer sobre alguns fenômenos que atravessam as experiências das professoras que atuam na Educação Infantil em tempo integral no estado do Espírito Santo.

\section{AS PERCEPÇÕES DAS PROFESSORAS ACERCA DA EDUCAÇÃO INFANTIL EM TEMPO INTEGRAL: ALGUMAS DISCUSSÕES}

No que diz respeito ao perfil dos participantes da pesquisa, todas são mulheres com idades entre 24 e 53 anos de idade, em grande parte (88\%) efetivas nos municípios em que trabalham, com atuação na Educação Infantil em tempo integral por um período que varia entre dois e 30 anos em contextos urbanos (55\%) e em contextos rurais (45\%). Há que se destacar que, a localidade em que as professoras se encontram não influiu nas respostas dos questionários, já que elas se aproximam entre si, permitindo-nos agrupá-las nas categorias de análise, sem necessidade de discriminar se os dados foram coletados com as professoras pertencentes às instituições de educação infantil em tempo integral dos contextos rurais ou urbanos.

Ao serem indagadas sobre as motivações que as levam a trabalhar com a educação em tempo integral, as professoras relatam que essa escolha ocorreu em virtude da realização de concurso 
público/processo seletivo; oferta de vagas somente em instituições que oferecem educação em jornada ampliada; preferência pela Educação Infantil independentemente do tipo de atendimento, tempo integral como única opção ofertada pelo município; possibilidade de cumprir a carga horária de 50 horas semanais; convite de algum profissional da gestão escolar. Somente duas professoras afirmam gostar de atuar na Educação Infantil em tempo integral, uma vez que a maioria delas parece estar nesse tipo de atendimento por outras questões, não atreladas à escolha própria.

As entrevistas são iniciadas com perguntas a respeito da "implementação" do tempo integral nas instituições de Educação Infantil. Sobre esse aspecto, as professoras destacam que a implementação do tempo integral se deu por conta de políticas públicas, motivadas, principalmente, pelo fato das familias - especialmente as mães - trabalharem fora de casa, bem como por questões relacionadas ao desemprego, pobreza, risco e vulnerabilidade social, pais usuários de droga, alimentação, contexto de vida socioeconômico e cultural carente demonstrando que, apesar dos avanços relacionados à educação da primeira infância, a Educação Infantil, principalmente quando relacionada ao tempo integral, ainda apresenta uma perspectiva assistencialista de estratégia de atendimento (ARAÚJO, 2015; 2017; SOUZA, 2012; RODRIGUES, 2012; JUNCKES, 2015; OLIVEIRA, 2016; MARCHIORI, 2012; CASSINS, 2016; BERNARDES, 2017). Complementando a discussão, Barbosa, Richter e Delgado afirmam que:

[...] desde o final do século XIX, foi se constituindo em nosso país uma prática polarizada entre assistência e escolarização que consolidou uma educação de turno integral para as crianças de classes populares, cujas mães exerciam atividades de trabalho em espaço extradoméstico; e uma educação em turno parcial para as crianças de classes médias e altas nos jardins de infância e nas pré-escolas, cujas mães trabalhavam meio período ou se dedicavam às atividades domésticas e/ou do lar. (BARBOSA; RICHTER; DELGADO, 2015, p. 96)

Quando indagadas se conhecem os critérios de matrícula, parte das professoras responde que predominam a ordem de chegada e as crianças moradoras da região em que a instituição de Educação Infantil está localizada, seguido de mães/famílias trabalhadoras e critérios socioeconômicos ligados ao risco e a vulnerabilidade social. Cabe destacar que "o direito ou os direitos se apresentam como uma igualdade normativa que apenas permite desigualdades fáticas justificáveis" (ARAÚJO; PEIXOTO, 2017, p. 77), pois, uma vez que o principal motivo da matrícula recai sobre uma necessidade da família, esse direito parece destinar-se a ela e não primordialmente às crianças como prevê as legislações educacionais. Chama-nos atenção que uma professora considera um absurdo mães que não trabalharem solicitarem vagas na Educação Infantil em tempo integral. No entanto, segundo as DCNEIS (BRASIL, 2010, p. 14), o dever do Estado com a Educação Infantil pressupõe que a oferta seja "pública e de qualidade, sem requisito de seleção", independente se a modalidade for em tempo parcial ou em tempo integral.

Contudo, naqueles municípios onde a oferta da Educação Infantil em tempo integral é maior do que a demanda das famílias, as professoras dizem que não há critérios discriminados de matrícula. 0 estabelecimento de critérios que asseguram a disponibilização de vagas no tempo parcial para famílias de classes mais altas e em tempo integral para famílias de classes populares é evidenciado por Barbosa, Richter e Delgado (2015) como uma contribuição para a produção de desiguais acessos aos direitos das crianças à educação como princípio essencial da democracia a partir da manutenção de uma lógica excludente pela especificação entre amparo para alguns e instrução para outros. 
A análise das professoras no que diz respeito à relação com o cotidiano familiar e escolar evidencia a transferência das responsabilidades familiares para a escola, configurando conceitos préestabelecidos na sociedade que ainda remontam à educação em tempo integral sob a concepção de lugar privilegiado de cuidado e guarda das crianças. No que diz respeito à questão da responsabilidade sobre a criança, tanto a Constituição da República em seu art. 205 (BRASIL,1988), quanto o ECA (BRASIL, 1990) no art. $4^{\circ}$, asseguram a educação como direito de todos e dever do Estado e da família, portanto, estabelecendo a relação família e escola, como um regime de colaboração, para que o direito da criança prevaleça. A respeito disso, Oliveira (2020, p. 124) afirma que "[...] a família não pode ser destituída de seu papel de importante agência educativa dos filhos em proveito da creche ou da pré-escola".

Sobre as experiências docentes e as "práticas pedagógicas" direcionadas às crianças que estão no atendimento em tempo integral, as professoras destacam a necessidade de planejamento de atividades diversificadas, criatividade e ludicidade como características fundamentais para o desenvolvimento de aprendizados significativos para as crianças. Elas também enfatizam a importância da articulação entre os diferentes profissionais como basilar na organização para um atendimento diferenciado e de qualidade, além disso, mencionam que estabelecem um diagnóstico junto às crianças para planejamento das atividades, importante aspecto no pensar as práticas pedagógicas por levar em consideração as opiniões das crianças, colaborando para uma dinâmica em que "a escola da infância pode contribuir para a escuta dos tempos individuais e favorecer a experiência de viver tempos coletivos" (BARBOSA; RICHTER; DELGADO, 2015, p. 110), a fim de superar a lógica da fragmentação do tempo cronológico em turno e contraturno e das experiências em "lúdicas" e "pedagógicas".

Isso pressupõe o reconhecimento das crianças como sujeitos sociais, culturais, ativos e potentes, um processo ainda em curso. Assim, pensar o tempo integral na Educação Infantil em conformidade aos direitos das crianças implica garantir seu bem-estar e desenvolvimento irrestrito, não as enxergar apenas como meros alunos reclusos e confinados nas instituições em que são adotadas práticas educativas escolarizantes que acabam por despotencializar as culturas infantis. Segundo Sarmento (2015, p. 71), a criança "[...] é 'marcada' pela sua presença em contexto institucional, onde realiza um conjunto de práticas sociais que são (ao menos parcialmente) intencionais e dirigidas pelos adultos e, assim, ela é envolvida em contextos de produção e reprodução cultural", logo, considerar o que as crianças desejam nos momentos de planejamento das aulas pode ajudar a desconstruir esse estatuto institucionalizador atribuído a elas.

Ainda no tocante às "práticas pedagógicas", segundo as professoras, as atividades planejadas para o trabalho com as crianças matriculadas no tempo integral seguem os direcionamentos apontados nos documentos federais, municipais e da escola (plano de curso, plano pedagógico e quadro de rotina). Como principais atividades, aparecem brincadeiras, jogos, movimento e recreação, seguidos de artes plásticas (pintura, modelagem e trabalho com sucata). Apesar de serem planejadas com maior frequência atividades relacionadas às artes plásticas, de acordo com a pesquisa, são as artes cênicas (teatro, dança e música) que despertam o maior interesse das crianças.

Contudo, parte das professoras afirma desenvolver atividades de leitura e de escrita voltadas para a alfabetização, fazendo-nos pensar que a experiência do tempo integral acaba sendo impregnada por um processo de escolarização advindo das etapas posteriores de ensino. Conforme Aquino (2015, p. 173), "[...] parece estar ocorrendo muito mais uma contaminação da educação infantil pelo ensino 
fundamental do que o inverso, como desejávamos". Bem sabemos que ensinar a ler e escrever não é o foco do trabalho cotidiano na Educação Infantil, a exemplo das DCNEIS (BRASIL, 2010), que apresentam como eixos norteadores das práticas pedagógicas as interações e as brincadeiras.

O estudo também revela que em grande parte dos municípios capixabas, não há um Projeto Político Pedagógico articulado às DCNEIS (BRASIL, 2010) que contemple as particularidades do tempo integral. Assim, nos chamam a atenção as distorções quanto aos objetivos da permanência das crianças em jornada ampliada. Em consequência disso, ganha centralidade $o$ trabalho de proteção $e$ provisão (sono, banho e alimentação), conferindo ao tempo integral um atendimento mais voltado às condições de vida das crianças e ao tempo parcial um caráter fundamentalmente pedagógico. A esse respeito, Araújo e Peixoto (2015) discorrem sobre a ampliação da permanência da criança na Educação Infantil em tempo integral questionando se tal tempo é proporcionalmente qualificado.

Para Oliveira (2020, p. 131), a qualidade educacional na Educação Infantil "[...] sem dúvida, depende do que é pretendido para as futuras gerações, ou seja, de um projeto político elaborado pelas comunidades escolares". Entretanto, a pesquisa revela que, tanto nos contextos urbanos quanto nos rurais, na maioria dos casos, as propostas administrativas e pedagógicas voltadas ao tempo integral não têm como referência a ampliação do universo cultural das crianças e a articulação com os espaços da cidade, evidenciando, dessa forma, fragilidades no planejamento e avaliação do trabalho pedagógico, bem como nas condições de trabalho e na formação dos profissionais.

Segundo as professoras entrevistadas, as atividades que despertam menor interesse das crianças estão relacionadas às atividades extensas que exigem grande concentração. Para Losso e Marchi (2011, p. 14), "embora, 'brincar' seja muito importante na educação infantil, muitas vezes os professores até esquecem que se trata de uma criança e a tratam como aluno", fazendo-se necessário "[...] recusar os modelos finalizados, os padrões e as rotinas rígidas [...] e partir das crianças e das suas práticas culturais para organizar a ação pedagógica" (SARMENTO, 2015, p. 81), de modo que o planejamento apresente atividades diversificadas, criativas e lúdicas, sendo estas, fundamentais para o desenvolvimento de aprendizados significativos e prazerosos para as crianças.

As professoras afirmam realizar atividades diversificadas com as crianças de acordo com os interesses manifestados por elas cotidianamente, mas sinalizam um descompasso no contato entre as famílias e o corpo docente, no que diz respeito aos projetos e atividades realizadas na instituição, em face à demanda das famílias por atividades de conscientização que se aproximem da realidade de vida das crianças, como por exemplo, vinculadas à educação sexual, à pedofilia, ao racismo e às drogas. Oliveira (2020) propõe que as famílias sejam acolhidas nas instituições educacionais para que elas sejam possibilitadas a apresentar os seus anseios, suas demandas e seus desejos em relação à educação dos seus filhos.

Ainda sobre as atividades, as famílias das crianças não diferenciam as propostas destinadas ao atendimento em tempo parcial ou em tempo integral, como se não versassem de especificidades distintas e nem devessem ser tratadas por meio de práticas variadas, sendo que essa é uma prática adotada pelas professoras. Segundo Araújo e Peixoto (2017, p. 84), o espaço da Educação Infantil necessita de "[...] uma dinâmica de trabalho que supere a dicotomia entre 'tempo parcial' e 'tempo integral' e se converta em uma experiência com múltiplas possibilidades educativas". Todavia, no que se refere às especificidades do tempo integral, Carvalho (2014) ressalta o desafio de compreender como as vivências de educação em tempo integral podem harmonizar com as experiências das crianças e construir novas formas de institucionalização da infância. 
A última categoria analisada diz respeito aos "desafios" enfrentados pelas professoras. Neste aspecto, apontam a escassez de recursos materiais e pedagógicos, brinquedotecas, parquinhos; alimentação e espaço físico inadequado, principalmente para crianças com deficiência, seguidos de formação continuada, comprometimento do próprio professor, exploração e construção de novos espaços/tempos na instituição com atendimento em tempo integral. A pesquisa evidencia que tais desafios também são enfrentados pela gestão escolar, sobretudo, aqueles relacionados às demandas financeiras necessárias para a elaboração e execução do projeto pedagógico com ações importantes à garantia da qualidade da educação, uma vez que os gestores possuem limitações na administração do orçamento, tendo, portanto, que renunciar à compra de equipamentos e materiais pedagógicos. Essa percepção dos gestores se aproxima das colocações das professoras ao direcionarem a crítica para a ausência de recursos didáticos que compromete o desenvolvimento das práticas pedagógicas.

As professoras estabelecem como principal dificuldade para desenvolver um bom trabalho na Educação Infantil em tempo integral a falta de material, seguida da falta de brinquedos, escassez de livros, falta de transportes para atividades fora da escola e remuneração condigna insuficiente, segundo elas, fatores que contribuem para a diminuição do comprometimento do professor. Vale destacar que, se tratando da Educação Infantil em tempo integral, a Estratégia 6.2 da Meta 6 do PNE visa "fomentar a articulação da escola com os diferentes espaços educativos, culturais e esportivos e com equipamentos públicos, como centros comunitários, bibliotecas, praças, parques, museus, teatros, cinemas e planetários". De acordo com Barbosa, Richter e Delgado (2015, p. 110), "uma escola em tempo integral, mais que uma escola em tempo parcial, exige abertura aos acontecimentos dos espaços públicos da cidade como modo de favorecer que as crianças aprendam a frequentar esses lugares e a torná-los seus". Para tanto, torna-se importante tanto a possibilidade de utilizar transportes escolares quanto, o interesse do professor com atividades que ultrapassem o espaço físico da instituição de Educação Infantil.

Outro desafio apontado pelas professoras são as diferenças em atuar no tempo regular e no tempo integral, ao afirmarem que o tempo integral exige maior diversificação de atividades e envolvimento do professor. Ressaltam ainda que o tempo integral é sinônimo de cuidar e por sua vez, o tempo parcial equivale ao educar. Tais afirmações revelam a produção de estigmas no contexto das instituições, visto que algumas crianças ficam reconhecidas como crianças do tempo integral e as demais como crianças da Educação Infantil (ARAújO, 2015).

Uma aparente "diferença" entre as crianças que permanecem na instituição no tempo integral e as que ficam apenas as quatro horas diárias referentes à jornada do tempo parcial, é evidenciado pelas professoras e se apresenta como um desafio às experiências propostas. Segundo as professoras entrevistadas, as crianças do tempo integral são mais agressivas e carentes, a nosso ver, tal asserção reafirma o estigma da "[...] figura do pobre carente e fraco, vítima e sofredor das desgraças da vida, fixados nas determinações inescapáveis das leis da necessidade" (TELLES, 1999, p. 178-179). Enquanto as crianças que frequentam o tempo regular, exprimem maior interesse pelas propostas apresentadas em sala, além de as professoras conseguirem manter uma relação mais próxima com as famílias dessas crianças. De acordo com Côco et al. (2010), o número de horas que compõe o tempo integral desencadeia maior cansaço das crianças e menor desempenho nas atividades, o que pode justificar o porquê das crianças que frequentam o tempo integral demonstrarem menos interesse nas propostas educativas.

Assim, o enfrentamento do cansaço das crianças bem como dos questionamentos sobre o desempenho no processo de escolarização pode ser articulado com a 
participação infantil na organização do trabalho, ressignificando o 'efeito da escola' na vida dos pequenos que vivem uma jornada de dez horas diárias na instituição de educação infantil e do trabalho dos diferentes profissionais que interagem com eles (CÔCO et al., 2010, p. 8).

A colocação de Côco et al. (2010) evidencia que as crianças percebem a ampliação do tempo no âmbito da Educação Infantil. A nosso ver, esse é mais um desafio enfrentado pelas professoras que lidam cotidianamente com as crianças. Há que se ressaltar que as professoras também afirmam sentir cansaço ao atuarem no tempo integral, revelando-nos que se trata de uma rotina desgastante tanto para as crianças quanto para os profissionais da educação.

Para identificar o grau de interesse das crianças pelas atividades, as professoras dizem utilizar como termômetro a conversa e a retomada das atividades, assim como as observações das atitudes e do comportamento das crianças durante o cotidiano escolar. No entanto, quando as crianças falam que estão cansadas, algumas professoras as questionam se é cansaço ou é preguiça, demonstrando entender que essa prática de confronto pode resolver o problema da falta de interesse delas. Peixoto, Schuchter e Araújo (2015) ressaltam a importância da compreensão e do aprofundamento da ideia de uma Educação Infantil em tempo estendido fundamentada a partir do conceito de experiência (BENJAMIN, 2005, p. 395, tradução nossa), em que é "[...] tarefa da infância: introduzir o novo mundo no espaço do simbólico" a partir da descoberta de "[...] novas imagens a serem incorporadas ao patrimônio de imagens da humanidade", desenvolvendo assim, práticas pedagógicas que produzam sentido para a criança tendo em vista a sua própria realidade de vida.

As professoras também destacam que, para a qualidade do atendimento na Educação Infantil em tempo integral em consonância com a legislação educacional, é fundamental que haja professores junto às crianças em todo o tempo de permanência na escola, pois em alguns momentos ao longo da jornada na instituição, não há professores disponíveis para o atendimento o os assistentes educacionais são designados assumirem a responsabilidade pela turma, ocorrência não observada no tempo parcial, já que as professoras permanecem durante toda a jornada de quatro horas diárias com as crianças.

\section{CONSIDERAÇÕES FINAIS}

A implementação do tempo integral na Educação Infantil está atrelada ao fato das famílias, principalmente as mães, trabalharem fora do lar, bem como a questões pertinentes a alimentação, a pobreza, ao desemprego, ao risco e vulnerabilidade social. Ainda que esse tipo de atendimento seja uma possibilidade de proporcionar proteção e provisão social às crianças, não podemos perder de vista que a sua implementação gira em torno, predominantemente, de demandas socioeconômicas das famílias, como se isso prevalecesse sobre o reconhecimento do direito à educação de seus filhos, razão primeira da Educação Infantil.

No que diz respeito às atividades pedagógicas, as professoras evidenciam a necessidade de planejamentos coletivos de atividades diversificadas, criatividade e ludicidade como características fundamentais para o desenvolvimento de aprendizados significativos para as crianças, bem como um atendimento diferenciado e de qualidade. Embora elas reconheçam a importância de tais atividades, apontam que realizam tarefas mecanicistas e percebem que isso gera desinteresse das crianças. Não obstante as dificuldades do trabalho docente na educação infantil e as contradições que as próprias 
professoras observam, a pesquisa oportunizou a elas, o (re) pensar das questões no/do/com/para o campo da educação da infância em tempo estendido.

Considerando os desafios enfrentados no cotidiano da Educação Infantil em tempo integral, as professoras acreditam serem necessários recursos materiais, maiores oportunidades de formação continuada e comprometimento do professor para que o atendimento em tempo integral tenha mais qualidade. Para tanto, torna-se necessário desalojar padrões estabelecidos e práticas cristalizadas com o propósito de assumir a "[...] responsabilidade de apresentar o mundo às crianças para que elas possam criar novos mundos [pois, temos compromisso] pelas questões que dizem respeito à vida das crianças" (ARAÚJO, 2017, p. 201).

Inspirada nas reflexões da pensadora Hannah Arendt, Almeida (2013, p. 232) questiona "Qual a responsabilidade do professor e da instituição escolar diante da criança e do mundo?" A essa instigante pergunta, Arendt (1990, p. 239) responde, "[...] face à criança, é como se ele [isto é, o professor] fosse um representante de todos os habitantes adultos, apontando os detalhes e dizendo à criança: - Isso é o nosso mundo". Se aqueles que chegaram primeiro ao mundo têm tantas responsabilidades em introduzir as novas gerações nesse mundo pré-existente cujos valores públicos são construídos historicamente, o que dizer do papel do professor em relação às crianças matriculadas na Educação Infantil em tempo integral que vivem em um contexto de intensas desigualdades sociais e econômicas? Qual a aposta ético-política desse tipo de atendimento ofertado às crianças?

Por fim, tendo em vista que a temática do tempo integral na Educação Infantil ainda é pouco explorada sob o ponto de vista acadêmico, as considerações aqui feitas não visam estabelecer generalizações sobre o tema, mas apresentar algumas reflexões advindas de nosso processo de análise e de pesquisa. Os resultados da investigação suscitam a necessidade de outros estudos acerca dos fenômenos relacionados às práticas pedagógicas pensadas para as crianças que frequentam o tempo integral nas instituições de Educação Infantil.

\section{REFERÊNCIAS}

ALMEIDA, Vanessa Sievers. Recém-chegadas e estranhas: as crianças e o mundo comum na obra de Hannah Arendt. Revista Educação Pública, Cuiabá, v. 22, n.49/1, p. 229-247, maio/ago. 2013.

ARAÚJO, Vania Carvalho de. O tempo integral na educação infantil: uma análise de suas concepções e práticas. In: ARAÚJO, Vania Carvalho de. (Org.). Educação infantil em jornada de tempo integral: dilemas e perspectivas. Vitória: EDUFES, 2015.

ARAÚJO, Vania Carvalho de. Educação infantil em tempo integral: em busca de uma philia social. Educar em Revista, Curitiba, n. 63, p. 191-203, jan./mar. 2017.

ARAÚJO, Vania Carvalho de; AUER, Franceila; TAQUINI, Rennati. Política de educação infantil em tempo integral: notas sobre a percepção das famílias. Jornal de Políticas Educacionais, Paraná, v. 15, n. 4, p.1-22, jan. 2021.

ARAÚJO, Vania Carvalho de; PEIXOTO, Edson Maciel. Tempo integral na educação infantil: uma nova "arte de governar crianças"? In: ARAÚJO, V. C. de. (Org.). Infâncias e Educação Infantil em Foco. Editora: CRV, 2017. 
ARENDT, Hannah. Entre o passado e o futuro. Tradução de Mauro W. Barbosa. 5. ed. São Paulo: Perspectiva, 1990.

BENJAMIN, Walter. Libro de lospasajes. Madrid: Ediciones Akal, 2005.

BERNARDES, Aline Arantes. A formação continuada em serviço dos professores da Educação Infantil na escola de tempo integral da Rede Municipal de Ensino de Campo Grande/MS. 2016. 120f. Dissertação (Mestrado em educação) - Programa de Pós-Graduação Mestrado e Doutorado em Educação, Universidade Católica Dom Bosco, Campo Grande, 2016.

BRASIL. Constituição Federal de 1988. Promulgada em 5 de outubro de 1988. Brasília, 1988. Disponível em http://www.planalto.gov.br/ccivil_03/constituicao/constituição.htm. Acesso em: 22 Fev. 2021.

BRASIL. Ministério da Educação. Lei no 9.394, de 20 de dezembro de 1996. Estabelece as diretrizes e bases da educação nacional. Brasília, 1996. Disponível em: http://portal.mec.gov.br/seed/arquivos/pdf/tvescola/leis/lein9394.pdf. Acesso em: 22 Fev. 2021.

BRASIL. Ministério da Educação e do Desporto. Conselho Nacional de Educação. Diretrizes Curriculares Nacionais para a Educação Infantil. Brasília: MEC/SEB, 2010. Disponível em: http://portal.mec.gov.br/index.php?option=com_docman\&view=download\&alias=9769diretrizescurriculares-2012\&category_slug=janeiro-2012-pdf\&Itemid=30192. Acesso em: 22 Fev. 2021.

CARVALHO, Levindo Diniz. Crianças e infâncias na educação (em tempo) integral. Educ. rev., Belo Horizonte, v. 31, n. 4, p. 23-43, dez. 2015.

CASSINS, Beatriz Conci. Um projeto construtivista na educação infantil em tempo integral. 2016. 215f. Dissertação (Mestrado em educação) - Programa de Pós-Graduação em Educação, Universidade Federal do Paraná, Curitiba, 2016.

CÔCO, Valdete; ZUCOLOTTO, Valéria M; EDIVÂNIA, Sousa de; SANTOS, Ma F. Santos.Tempo integral na educação infantil: reflexões a partir de referências de pedagogos. Universidade Federal do Espírito Santo, 2010. Disponível em: www.sbhe.org.br/novo/congressos/cbhe6/anais_vi_cbhe/conteudo/file/542.doc.Acesso em: 20 de fev. 2021.

GIL, Antonio Carlos. Métodos e Técnicas de Pesquisa Social. 6. ed. São Paulo: Editora Atlas S.A, 2008.

JUNCKES, Cris Regina Gambeta. Escola de tempo integral e o direito à infância: uma análise da produção acadêmica (1988-2014). 2015. 214f. Dissertação (Mestrado em educação) - Programa de Pós-Graduação em Educação, Universidade Federal de Santa Catarina, Santa Catarina, 2015.

KUHLMANN JUNIOR, Moysés. Infância e educação infantil: uma abordagem histórica. Porto Alegre: Mediação, 1998.

KUHLMANN JUNIOR, Moysés. Histórias da educação infantil brasileira. Revista Brasileira de Educação, Rio de Janeiro, n. 14, p. 5-18, maio/ago.2000.

MARCHIORI, Alexandre Freitas. A criança como "sujeito de direitos" no cotidiano da Educação Infantil. 2012. 194f. Dissertação (Mestrado em educação) - Programa de PósGraduação em Educação, Universidade Federal do Espírito Santo, Vitória, 2012. 
OLIVEIRA, Cristiane Elvira de Assis. Temporalidades no/do cotidiano da educação infantil. 2012. 158f. Dissertação (Mestrado em educação) - Programa de Pós-Graduação em Educação, Universidade Federal de Juiz de Fora, Juiz de Fora, 2012.

OLIVEIRA, Maxwell Ferreira de. Metodologia científica: um manual para a realização de pesquisas em administração. Catalão: UFG, 2011.

OLIVEIRA, Zilma de Moraes Ramos de. Educação infantil.8 ed. São Paulo: Cortez Editora, 2020.

PEIXOTO, Edson Maciel; SCHUCHTER, Terezinha Maria; ARAÚJO, Vania Carvalho de. O tempo integral na educação infantil: financiamento, gestão e projeto político-pedagógico em questão. In: ARAÚJO, V. C. de. (Org.). Educação infantil em jornada de tempo integral: dilemas e perspectivas. Vitória: EDUFES, 2015. p. 125 - 161.

RODRIGUES, Juliana Beatriz Machado. A construção de uma escola de educação infantil de tempo integral: "Cavando os achadouros da infância". 2012. 146f. Dissertação (Mestrado em educação) - Programa de Pós-Graduação em Educação, Universidade Regional do Noroeste do Estado do Rio Grande do Sul, Ijuí, 2012.

SARMENTO, Manuel Jacinto. Para uma agenda da educação da infância em tempo integral assente nos direitos da criança. In: ARAÚJO, Vania Carvalho de (Org.). Educação infantil em jornada de tempo integral: dilemas e perspectivas. Vitória: EDUFES, 2015. p. 59-91.

SOUZA, Ediléia Alves Mendes. Prática pedagógica de qualidade na educação infantil em escola de tempo integral: visão de professores. 2012. 147f. Dissertação (Mestrado em educação) - Programa de Pós-Graduação em Educação, Universidade de Brasília, Brasília, 2012.

Submissão: 20/03/2021

Aceito: 04/06/2021

\footnotetext{
' Em busca realizada no Banco de Dados da Capes, usando como descritores "educação infantil" AND "tempo integral AND "professoras", encontramos apenas sete trabalhos relacionados às práticas pedagógicas na educação infantil em tempo integral, sendo o primeiro deles publicado em 2012.

ii Pesquisa denominada "Educação em tempo integral na educação infantil: um estudo das concepções e práticas no estado do Espírito Santo" realizada a partir de um Termo de Cooperação Técnica entre o Ministério da Educação/SEB/COEDI e a Universidade Federal do Espírito Santo, e com financiamento FNDE.

iii Após análise inicial e divulgação dos resultados gerais do estudo em 2015, mostrou-se necessário aprofundamento das percepções das professoras, cuja análise dos dados inicialmente coletados pela pesquisa de Araújo (2015) foram analisados nesse estudo.

${ }^{i v}$ A Lei Estadual no 9.768/11 apresenta a divisão dos municípios capixabas em Microrregiões e Macrorregiões.

v No original: "Tarea de la infancia: introducir el nuevo mundo em el espacio simbólico" / "nuevas imágenes para incorporarlas al patrimonio de imágenes de la humanidad".
} 